\title{
Development of the Question Items for the Scale of Quality of Life in Adult and Elder with Hearing Loss
}

\author{
Sungil Park ${ }^{1,2}$, Jinsook Kim² \\ 'Department of Speech Pathology Therapy and Aural Rehabilitation, Woosong University, Daejeon, Korea \\ ${ }^{2}$ Divison of Speech Pathology and Audiology, Research Institute of Audiology and Speech Pathology, College of Natural Sciences, \\ Hallym University, Chuncheon, Korea
}

\section{청각장애 장노년기의 삶의 질 척도를 위한 문항 개발}

박 성 일 ${ }^{1,2}$ 김 진 숙

우송대학교 언어치료청각재활학부 ${ }^{1}$, 한림대학교 자연과학대학 언어청각학부· 청각언어연구소 ${ }^{2}$

\begin{abstract}
Purpose: This study was to develop the quality of life (QOL) scale for adult and elder with hearing loss. Methods: 500 hearing impaired who were over 50's participated. Firstly, 52 preliminary question items selected out of 100 key words were analyzed with average, standard deviation, skewness, kurtosis, correlation coefficient and variance inflation factor. Secondly, exploratory factor analysis was conducted. Prior to this analysis, Kaiser-Meyer-Olkin (KMO) and sphericity of Barlett were confirmed to validate the suitability of the process. Finally, confirmatory factor analysis was conducted with convergent and discriminant validities. To verify fitness measurement of the factor model, Turker-Lewis index (TLI), root mean error of approximation (RMSEA), comparative fit index (CFI) were also measured. Results: The values of average, standard deviation, skewness, kurtosis, correlation coefficient and variance inflation factor were within a permitted limit of discrimination and normality of 52 preliminary question items. The KMO value was 0.930 and Barlett value was 8886.460 ( $p$ $<0.001$ ). Through exploratory factor analysis, final five factors and 31 items were extracted. This final items were named as quality of life in adult and elder with hearing loss (QOL-AEHL). Confirmatory factor analysis confirmed the high internal consistency showing over 0.7 at construction reliability for all five final factors. The value of TLI, CFI, RMSEA were $0.862,0.874$, and 0.063 verifying suitability of fitness measurement of the factor model. Conclusion: QOL-AEHL can be a useful tool to enhance the quality of life for the hearing impaired. Further study should be performed for standardization for practical application.
\end{abstract}

Key Words: Quality of life, Quality of life in adult and elder with hearing loss, Factor analysis, Hearing loss, Adult and elder.

Received: October 6, 2016 / Revised: November 3, 2016 / Accepted: December 10, 2016

Correspondence: Jinsook Kim, Divison of Speech Pathology and Audiology, College of Natural Sciences, Hallym University, 1 Hallimdaehak-gil, Chuncheon 24252, Korea

Tel: +82-33-248-2213 / Fax: +82-33-256-3420 / E-mail: jskim@hallym.ac.kr

\section{INTRODUCTION}

의학이 발달되고 생명이 연장되면서 인류는 생존보다는 삶 의 질에 대한 관심이 증가하게 되었다. 주로 사회학 분야에서 논의 되던 삶의 질은 최근에는 다양한 인구집단에서 특정 질병 과 관련한 범위로 그 평가 영역이 점차 확대되고 있다. 전반적인 삶의 질을 평가하는 도구로 세계보건기구(World Health Organization)가 정의한 삶의 질에 근거하여 제작한 세계보건기구 삶의 질 척도(World Health Organization Quality of Life,
WHOQOL)가 있다(Harper, 1998). 총 100문항으로 구성되어 비교적 넓은 개념의 삶의 질을 일반적으로 측정하는 도구이다. 이를 축약한 총 26 문항으로 구성된 WHOQOL-BREF도 개 발되어 간단히 일반적인 삶의 질을 평가하도록 되어 있다. Min et al.(2000)은 WHOQOL과 WHOQOL-BREF를 번역하고 표 준화하여 국내에서 사용할 수 있도록 정리하였다. 그러나 저자 는 지침서에서 WHOQOL과 WHOQOL-BREF는 전반적인 건 강상 삶의 질 척도는 측정하지만 특정 질환에 대한 정확한 평가 가 이루어지지 못하고 있다고 보고하며 특정 질환에 대한 삶의 
질 평가 도구 개발의 필요성을 제시하였다. 현재 개발된 특정질 환에 대한 삶의 질 평가 도구로는 암환자의 삶의 질을 평가하 는 도구인 Karnofsky \& Burchenal(1949)이 개발한 Karnofsky Performance Index를 비롯하여 Padilla et al.(1983)이 개발한 Quality of Life Index, Cella et al.(1997)이 개발한 Functional Assessment of Cancer Therapy-General, 유럽의 암 연구 치 료기관에서 암환자의 삶의 질 도구로 지정한 Aaronson et al.(1993)이 개발한 Quality of Life Questionnaire-C30 등이 있 다. 국내에서는 Lee(2007)가 개발한 암 환자의 삶의 질을 평가 하는 Cancer-Quality of Life (C-QOL)가 있다. 또 다른 특정 질환의 삶의 질 평가도구로는 알레르기비염 환자들의 삶의 질 을 평가로 Juniper et al.(2003)이 개발한 Nocturnal Rhinoconjunctivitis Quality of Life Questionnaire, Boyer \& Earp(1997) 이 개발한 당뇨병 환자들의 삶의 질을 평가하는 Diabetes-39가 있다. 국내에서는 Lee(2014)가 개발한 한국판 알레르기 비염 환 자의 삶의 질 척도 Korean Allergic Rhinitis-Specific Quality of Life Questionnaire (RQLQ)가 있다. RQLQ의 문항 중에는 '코가 막혀 숨쉬기가 힘들다', '알레르기비염으로 일을 처리하는 능력이 떨어진다' 등의 특정질환과 관련된 구체적 질문을 포함 하고 있다.

이와 같이 특정질환에 대한 삶의 질 평가도구가 일반적인 삶 의 질 평가 도구와 달리 개발된 것은 각 질환의 특정 상황이 삶 의 질에 다른 영향을 줄 수 있기 때문이다. 더욱이 의사소통 장 애로 사회적 능력에 저하가 우려되는 청각장애인의 삶의 질 평 가는 건청인이나 다른 특정 질환을 가진 사람들과는 다르게 평 가되어야 한다. 왜냐하면 청각장애 때문에 발생하는 다른 삶의 질을 평가하려면 의사소통의 결여 및 단절 등이 미치는 영향을 평가할 수 있는 구체적인 문항들이 포함이 되어야 하기 때문이다. 현재 사용되고 있는 청각장애인의 삶의 질을 평가하는 도구로는 아동을 대상으로 한 Ravens-Sieberer \& Bullinger(1998)가 개 발한 자기평가설문지인 Kinder Lebensqualitätsfragebogen (KINDL)이 있고 11 18세 사이 농이거나 난청이 심한 청소년 들을 대상으로 삶의 질을 평가하는 Patrick et al.(2011)이 개발 한 Youth Quality of Life Instrument-deaf and Hard of Hearing Module (YQOL-DHH)이 있다. 또한 Umansky et al.(2011) 이 개발한 Hearing Environments and Reflection on Quality of Life (HEAR-QL)도 아동을 대상으로 많이 사용되고 있다. 그러나 삶의 질 평가는 대상연령에 따라 달라질 수 있으므로 아동을 대상으로 한 삶의 질 평가도구는 청각장애가 많이 발 생하는 장노년기 청각장애의 삶의 질 평가도구로 사용할 수는 없다. 또한 문항들을 조금씩 바꾸어 사용하거나 한국어로 번역 해서 사용할 경우 문화와 정서적 차이로 적절한 평가를 하기가 쉽지 않고, 번역 과정에서 평가의 초점이 변질되어 신뢰도와 타
당도가 저하될 수 있어 번역본을 사용하는 것도 적절치 않다. 더욱이 산업소음과 휴대용 음향기기 사용의 확대로 50 대의 청 각장애 출현율이 증가하고 있어 청각장애로 인한 삶의 질 변화 에 대한 평가 도구의 필요성이 절실해지고 있다. 더욱이 50대는 아직 사회생활을 하고 있는 연령으로 의사소통의 필요성도 크 기 때문에 청각장애로 인해 삶의 질에 대한 영향이 크고 그에 대한 도움도 매우 필요한 연령대의 인구이다. 또한 인구의 고령 화로 점차 증가하고 있는 60 대 이상의 노년기에 자주 나타나는 청각장애로 인한 노년기의 삶의 질 변화에 대한 평가의 필요성 은 더 이상 강조할 필요가 없을 정도이다. 결론적으로 청각장 애 인구가 많은 장노년기를 대상으로 한 국내의 청각장애인을 위한 삶의 질 평가 도구 개발이 필요하다.

따라서 본 연구는 장노년기를 대상으로 의사소통의 결여 및 단절을 초래하는 청각장애가 미치는 삶의 질 영역을 요인별로 평가할 수 있는 구체적 문항을 개발하고자 하였다.

\section{MATERIALS AND METHODS}

\section{연구 대상}

예비문항을 50 개 내외로 선정하고 그에 적절한 연구 대상의 수를 결정하고자 하였다. 왜냐하면 변수 간 상관분석에 의거하 여 시행되는 요인분석을 실시하여 문항을 개발하고자 할 때 상 관분석을 신뢰할 수 있도록 충분한 사례수를 확보하여야 하기 때문이다. Cho(2003)는 평가 문항을 개발할 때 문항수의 최소 5 배 내지 10 배가 연구 대상자의 수로 가장 적절하다고 하였으 므로 본 연구의 연구 대상을 500 명으로 설정하였고 동의서를 작성한 대상 500 명이 본 연구 분석에 참여하였다. 대상자는 전 국의 노인종합복지관, 청각장애 복지관, 보청기센터 등을 방문 하여 시설 및 센터를 이용하는 50대 이상의 청각 장애를 가진 분들 중 연구 내용에 대한 설명을 듣고 자의로 동의서를 작성 한 대상으로 하였다. 연구 대상의 인구통계학적인 분석은 Table 1 과 같다.

\section{문항 개발절차}

\section{청각장애 삶의 질 개념 기틀 선정 및 평가 영역 추출}

삶의 질 개념 기틀을 확립하기 위해 2015년 1월에서 3월까지 20 명의 장노년기 청각장애인을 표본 집단으로 선정하여 심층면 담을 20 40분 정도 실시하였다. 면담 시에 주로 사용한 질문 은 “질적인 삶(안녕 혹은 만족감)이란 무엇을 의미하는가?", "난 청이 삶의 질 중 어떠한 부분에 영향을 미쳤는가?”, “삶의 질에 영향을 미치는 요인들은 무엇인가?", "잘 듣기 위해 필요한 것 이 무엇인가?, 어떻게 하면 난청이 개선될 수 있는가?” 등이었 
Table 1. Demographic data

\begin{tabular}{|c|c|c|}
\hline & $\mathrm{n}$ & $\%$ \\
\hline \multicolumn{3}{|l|}{ Sex } \\
\hline Male & 233 & 46.6 \\
\hline Female & 267 & 53.4 \\
\hline \multicolumn{3}{|l|}{ Area } \\
\hline Kyunggi & 91 & 18.2 \\
\hline Jeonra & 75 & 15 \\
\hline Kwangwon & 25 & 5 \\
\hline Kyungsang & 85 & 17 \\
\hline Seoul & 105 & 21 \\
\hline Busan & 65 & 13 \\
\hline Chungchung & 54 & 10.8 \\
\hline \multicolumn{3}{|l|}{ Age } \\
\hline 50 & 60 & 12 \\
\hline 60 & 118 & 23.6 \\
\hline 70 & 200 & 40 \\
\hline 80 & 119 & 23.8 \\
\hline 90 & 3 & 0.6 \\
\hline \multicolumn{3}{|l|}{ Religion } \\
\hline Protestantism & 102 & 20.6 \\
\hline Buddhism & 213 & 42.9 \\
\hline Catholic & 57 & 11.5 \\
\hline Atheism & 113 & 22.8 \\
\hline Etc & 11 & 2.2 \\
\hline \multicolumn{3}{|l|}{ Education } \\
\hline Iliteracy & 21 & 4.2 \\
\hline Elementary & 134 & 36.9 \\
\hline Middle school & 144 & 28.9 \\
\hline High school & 125 & 25.1 \\
\hline University & 67 & 13.5 \\
\hline Graduate niversity & 7 & 1.4 \\
\hline \multicolumn{3}{|l|}{ Hearing level } \\
\hline Mild & 144 & 28.8 \\
\hline Moderate & 144 & 28.8 \\
\hline Moderate to severe & 120 & 24.0 \\
\hline Severe & 92 & 18.4 \\
\hline \multicolumn{3}{|l|}{ Marital } \\
\hline Single & 17 & 3.4 \\
\hline Married & 300 & 60.1 \\
\hline divorce & 45 & 9.0 \\
\hline Remarriage & 25 & 5.0 \\
\hline Bereavement & 108 & 21.6 \\
\hline Etc & 4 & 0.8 \\
\hline \multicolumn{3}{|l|}{ Pocket money } \\
\hline Under 100,000 won & 148 & 29.6 \\
\hline $100,000-300,000$ & 189 & 37.8 \\
\hline $300,000-500,000$ & 80 & 16.0 \\
\hline $500,000-1,000,000$ & 64 & 12.8 \\
\hline Over $1,000,000$ & 16 & 3.2 \\
\hline Etc & 3 & 0.6 \\
\hline
\end{tabular}

Table 1. Demographic data (continued)

\begin{tabular}{lrr}
\hline & $\mathrm{n}$ & $\%$ \\
\hline Income & 84 & 16.8 \\
Under 500,000 won & 57 & 11.4 \\
$500,000-1,000,000$ & 35 & 7.0 \\
$1,000,000-1,500,000$ & 53 & 10.6 \\
$1,500,000-2,000,000$ & 117 & 23.4 \\
Over 2,000,000 & 154 & 30.8 \\
Etc & & \\
Frequency of go out & 259 & 51.8 \\
Everyday & 185 & 37.0 \\
One time in a week & 29 & 5.8 \\
One time in two week & 12 & 2.4 \\
One time in three week & 9 & 1.8 \\
One time in a month & 6 & 1.2 \\
Etc & & \\
Hearing aid & 204 & 40.8 \\
Use & 296 & 59.2 \\
Not use &
\end{tabular}

다. 답변 중 면담을 통해 추출된 청각장애 장노년기의 삶의 질 에 대한 구성용어를 정리하고 삶의 질 연구와 관련된 연구들을 분석하여 건강, 자존감, 가족관계, 대인관계 등 네 개의 평가 영 역을 추출하였다. 더욱이 면담을 통해 청각장애인의 삶의 질 평가는 전반적인 건강에 대한 삶의 질 항목보다는 대인관계에 대한 항목들이 중요하다는 것을 확인하였고 그에 따라 그러한 문항에 비중을 두어 예비문항들을 작성하였다. 또한 본 연구에 서 개발하고자 하는 문항은 장노년기를 대상으로 하고 있기 때 문에, 장노년기의 신체적, 인지적 기능을 고려한 문항을 포함해 야 하는 필요성도 고려하였다.

\section{예비문항 선정}

유용한 한국 청각장애 장노년기의 삶의 질을 측정하는 문항 을 좀 더 적절한 방법으로 개발하고자 사회과학 교수 1 명, 국문 과 교수 1 명, 통계학과 박사 1 명, 석사 1 명과 청각학 교수 3 명으 로부터 자문을 구하였다. 또한 선정된 내용이나 용어가 이해하 는데 문제가 없는지 확인하기 위해 60대 노인 4명으로 구성된 노년기 자문단을 형성하여 문구 등을 검토하였다. 상기의 개념 기틀 선정 및 평가영역 추출에 근거하여 다음과 같은 총 3단계 의 작성과정을 거쳐 최종예비문항을 선정하였다.

1단계: 개념기틀에서 제시된 주요영역과 하위영역에 따라 도 출된 중심단어로 추출된 100 여 개의 단어 중에서 중복되는 단 어를 제외하고 주요 단어 80 개 이상을 추출하였다. 기존 삶의 질 설문지 내용과 비교하면서 청각장애의 특성이 고려된 삶의 질 평가 문항인 100 개 문항으로 1 차 예비조사 설문지를 작성하 였다. 
2단계: 작성된 예비 설문지를 삶의 질 연구의 개념기틀, 문항 구성내용 영역 및 척도의 타당성에 대한 부분을 사회학과, 국문 과, 통계학과의 교수 및 박사로 구성된 전문 자문단과 노년기 자 문단에게 자문을 의뢰하여 문항이 애매모호한 것과 중복된 것 은 수정하고 80 개 문항으로 2차 예비조사 설문지를 작성하였다.

3 단계: 2 차 예비조사 설문지의 내용 타당도 검증을 위해 청 각학 교수 3 명, 노인복지관 관장 5 명, 노인 복지관 담당자 10 명 에게 검토를 의뢰하였다. 연구의 목적과 취지를 설명하고 협조 를 구한 뒤 설문지를 배포하고 일주일 후 회수하여 의견을 수렴 하고 설문지를 수정하였다. 이 과정에서 설문지 문항에 대한 응 답 방식은 “전혀 그렇지 않다(1점)" "그렇지 않다(2점)", “그저 그 렇다(3점)", “조금 그렇다(4점)", ”매우 그렇다(5)”의 5점 척도가 가장 효율적인 점을 확인하였고, 그 척도를 개발하는 설문지에 적용하였다. 점수는 각 문항당 1점에서 5점이고 점수가 높을수 록 삶의 질이 높은 것으로 해석되도록 하였다. 중심단어를 활용 하여 총 80 개의 문장을 완성하였고, 이를 내용타당도 The Content Validity Index가 0.8 이상인 문항으로 설정하여 예비문 항을 구성하였다. 또한 부정문과 긍정문 내용을 수정하여 일관 된 응답방향이 되도록 조정하였다. 이러한 진행 과정에서 건강, 자존감, 가족관계, 대인관계로 범주화된 네 개의 영역에서 총 52 개의 최종 예비문항이 선정되었으며 10 개의 하위 개념: 1) 신체적 건강, 2) 정신적 건강, 3) 경제적 상황, 4) 여가, 5) 일 또는 직업, 6) 심리적 자존감, 7) 가족관계, 8) 만남 및 모임, 9) 협력관계, 10) 심리적 대인관계를 추출하였다. 이 52 개의 최종 예비문항은 하위 개념들을 평가할 수 있는 세부적 문항 내용들을 검토하고 청각학과 관련된 전문인의 자문내용을 토대로 분석한 후 최종 예비문항으로 선정하였으며, 최종적으로 어휘의 난이도와 이해 도를 조절하기 위해 국문학과 교수에게 자문을 의뢰하여 문항 을 수정 보완하였고 청각장애를 가진 노인 10명을 대상으로 검 사하여 중복되거나 이해가 어려운 문항을 골라내어 수정한 후 최종 예비문항으로 구성하였다(Appendix 1).

\section{자료 수집}

본 연구는 한림대학교 연구윤리위원회(Institutional Review Board, IRB)의 심의에서 승인을 받아 진행하였다(심의번호: HIRB-2015-044). IRB의 내용에 근거하여 연구자는 본 연구 의 목적과 진행절차, 연구 참여의 자율성, 비밀보장 등에 대해 설 명하고 연구 참여를 통해 불이익이 발생하지 않는다는 점과 자 율적 참여 등에 대한 설명을 한 후 동의서에 서명한 대상자에게 만 개별적 면담을 통해 자료를 수집하였다. 전국의 노인종합복지 관, 청각장애 복지관, 보청기센터 등을 방문하여 시설 및 센터를 이용하는 50세 이상의 청각 장애를 가진 분들을 대상으로 설문 지를 작성하였다. 정량적 청력검사는 병원이나 보청기 센터 등
에서 실시하였고 복지관이나 개별 장소일 경우 이동식 청력검사 기를 통해 청력정도를 측정하여 청력장애를 확인하였다. 면담 및 설문지 작성 시간은 대략 10 20분 정도 소요되었다.

\section{문항 분석 과정}

삶의 질 문항을 검증하기 위하여 두 차례의 설문 조사를 실시 하였다. 우선 250명을 대상으로 1차 설문조사를 실시하여 총 52 개의 문항으로 구성된 삶의 질 예비문항들 간의 하위 요인구조 를 탐색하고, 개발될 척도에 사용될 수 있는 문항인지 확인하 고, 공통적인 부분들이 있는지 확인하여 통합하는 과정에서 요 인분석 중 탐색적 요인분석과 확인적 요인분석을 실시하였다.

\section{문항 분석}

52 개의 예비 문항을 평균, 표준편차, 왜도, 첨도의 표준점수, 상관계수, 분산팽창지수로 문항분석을 실시하였다. 평균이 2.0 이하이거나 4.5 이상인 경우, 혹은 표준편차가 0.8 이하이면 삶 의 질이 높은 사람과 낮은 사람을 잘 변별해 주지 못하는 항목 으로 생각되어 제거하여야 하고 응답의 편중도를 보여주는 왜 도와 첨도의 경우, 표준점수의 절대 값이 3.29 이상인 문항은 통계적 기준에 벗어나 정규성을 만족하지 못하는 것으로 보아 제거하여야 한다(Choi, 2007). 또한 삶의 질 설문지의 총점과 각 문항 응답 간의 상관계수를 분석하여 0.4 이하이면 전체 삶 의 질과 무관한 것으로 보아 해당되는 문항을 제거하였다. 또 한 분산팽창지수는 다중공선성을 확인하는 지수인데, 이는 중 복된 문항이 있는지 확인하여 제거 또는 통합할 수 있게 하여 준다. 분산팽창지수가 10 이상이 되면 동일한 문항으로 생각되 어 그 문항을 제거하여야 한다. 예를 들어 '건강영역' 중 ‘나는 인생을 즐기지 못 한다'와 '나의 삶은 매우 의미가 없다' 문항의 응답이 동일한 응답 비율이 많이 나타나게 되면 그 질문은 동 일한 것을 물어보는 중복된 문항으로 생각되기 때문에 두 문항 중 한 개를 제거하였다.

\section{탐색적 요인분석}

유사한 특성으로 문항들이 구성되는 요인들을 추출하기 위 해 탐색적 요인분석을 실시하였다. 탐색적 요인분석을 절차를 보면 먼저 모든 변수들에 대한 상관행렬을 구한 다음 각각의 요 인을 추출한다. 그 다음으로 보다 나은 해석을 위해 요인들을 회전시킨다. 마지막으로 각 응답자에 대한 요인들의 점수를 산 출한다. 상관행렬에서는 문항들이 탐색적 요인분석을 할 수 있 는 문항들인지 확인하기 위하여 Kaiser-Meyer-Olkin (KMO) 과 Bartlett 구형성 검정을 먼저 실시하였다. 왜냐하면 $\mathrm{KMO}$ 는 표본과 변수의 수의 적절성에 대한 검정통계량으로 값이 0.8 보다 크면 일반적으로 적절한 표본과 변수의 수로 판정하기 때 
문이다. Bartlett 구형성 검정은 요인분석에서 사용하는 상관계 수의 행렬의 대각행렬이라는 귀무가설에 대한 검정으로 독립변 수 간, 즉 52개 예비 문항 간의 상관관계가 없음을 의미하는 것 으로 검정통계량이 0.05 이하이면 탐색적 요인분석이 가능한 데 이터구조라고 판정할 수 있다(Choi \& Park, 2007).

요인을 추출하는 방법으로는 주성분분석(principle component analysis)과 공통요인분석(common factor analysis) 두 가 지가 있는데, 다양한 변수들의 분산 중 가급적 많은 부분을 설 명하는 소수의 요인을 추출할 수 있는 주성분분석 방법을 사용 하였다. 요인을 회전시키며 걸러내는 작업 중 직교회전인 vari$\max$ 회전과 사각회전인 oblique 방법이 있는데, 본 연구의 자료 처럼 요인들이 서로 독립적이면서 변수 군집들도 서로 독립적 일 때는 varimax를 사용하는 것이 타당하여 이 방법을 사용 하여 몇 개의 요인이 추출되는지를 확인하였다. 이러한 과정을 통해 먼저 요인별 상관관계를 확인한 후 각 요인별로 얼마나 요 인들을 설명하고 있는지를 보는 요인부하량 분석을 통해 최종 적으로 문항을 선정하였다. 상관관계 분석에서 요인별 상관계 수가 높으면, 서로 독립적이지 못하기 때문에 문항이 적절하지 못하여 재고하여야 한다. 다음으로 각 문항 중 10 번의 반복회 전을 통해 고유값이 1 이상인 요인을 추출하는데, 일반적으로 고유값이 크면 클수록 추출된 요인이 변수들의 분산을 잘 설 명하고 있다는 것을 의미한다(Choi \& Park, 2007). 본 연구에서 는 고유값이 1 이상인 요인을 우선 추출하였고, 추출된 요인 중 척도의 간명성을 높이기 위해 요인부하량이 0.5 이상인 문항만 선정하였다. 최종적인 요인을 추출하기 위해 요인부하량 0.5 이 상 되는 문항이 3 개 이상 속해 있는 요인만을 추출하도록 하였 다. 다음으로 각 요인들에 대한 신뢰도 분석을 통해 크론바흐 알파(Cronbach's $\alpha$ ) 값으로 내적 일관성을 검증하였다.

\section{확인적 요인분석}

확인적 요인 분석은 삶의 질을 구성하는 요인과 각 요인에 영향을 주는 하위 문항들의 구조가 적합한지 분석하는 과정이 다. 그러므로 여러 개의 문항이 하나의 요인에 영향을 어떻게 주는지 분석하는 구조모형을 구축하여 확인적 요인분석을 실 시한다. 본 연구에서 구축한 구조모형도는 Figure 1과 같다.

1 차 설문조사와는 다른 대상자 250명을 대상으로 2차 설문 조사를 실시하여 확인적 요인분석을 실시하였다. 구조모형의 적합도 평가에 앞서, 자료들이 확인적 요인분석에 적합한지 검 증하기 위하여 몇 가지 사전분석이 이루어졌다. 먼저 다섯 개 요인 31개 문항들을 대상으로, 각 잠재요인별 측정항목의 내적 일관성을 검증하기 위하여 신뢰도를 Cronbach's $\alpha$ 로 분석을 실시하였고, 각 문항이 삭제된 경우의 신뢰도 계수를 함께 검토 하여 추가적으로 제거되어야 하는 문항이 없는지 살펴보고자

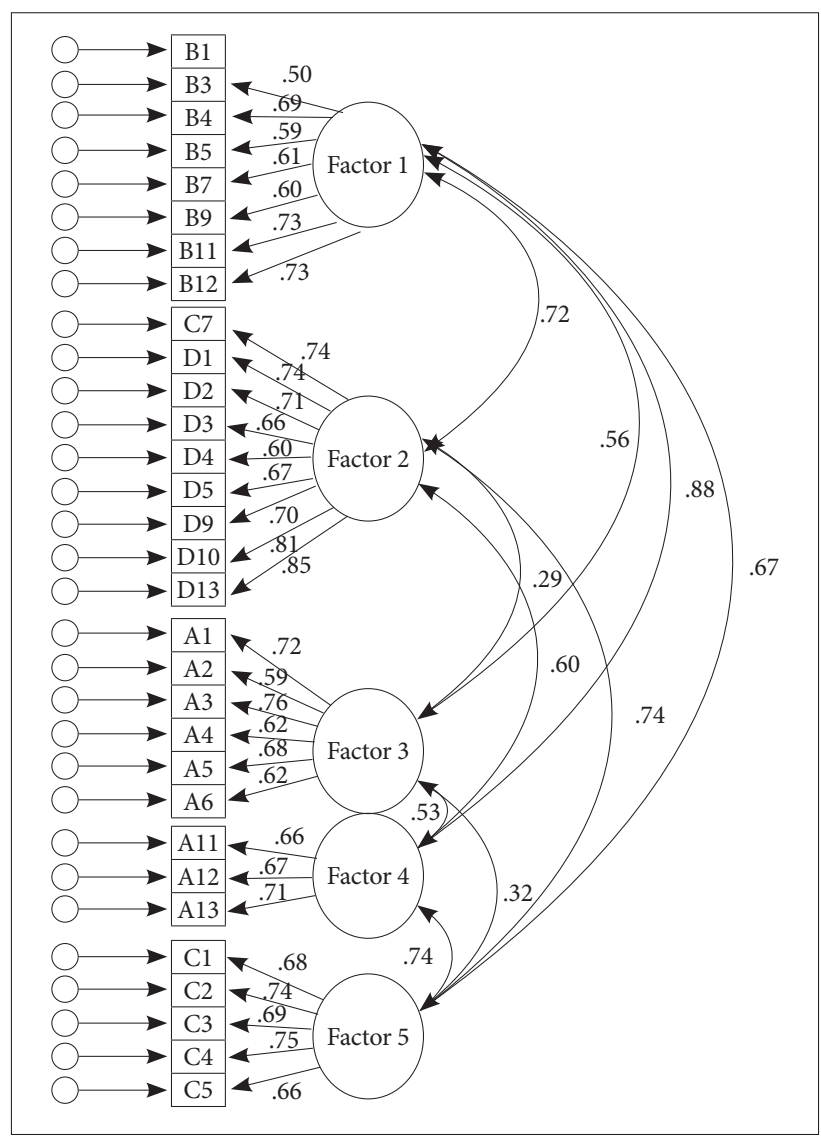

Figure 1. Structure model and standardized path coefficient.

하였다.

확인적 요인분석을 실시하기 위해서 공통요인으로 묶이지 않 는 중요도가 낮은 변수를 제거하는 구성타당도를 먼저 검증해 야 한다. 이 구성타당도는 구성개념과 그것을 측정하는 변수 사 이의 일치성을 검증하는 것인데 구성개념이 관측변수에 의해 얼 마나 잘 측정되었는지를 확인하는 방법으로 집중 타당도와 판별 타당도를 사용한다. 요인 수효에 대한 통계적 검증으로 모집단에 일반화할 수 있는 최대우도법(Maximum likehood method)을 사용하여 확인적 요인분석을 하였다. 일반적으로 집중타당도를 검증하기 위해 각 요인별 하위 문항들을 설명해 주는 요인적재 량과 임계비(critocal ratio)를 통해 집중타당도를 검증한다. 요 인적재량을 표현하는 표준화요인부하량이 0.5 이상이고 임계비 가 1.96 이상이면 구성개념을 일관되게 잘 측정하고 있다고 판 단할 수 있어 적합한 문항으로 볼 수 있다(Hong, 2000). 이러 한 과정에서 개념 신뢰도가 산출되는데, 표준화된 요인적재량 합의 제곱을 표준화된 요인적재량 합의 제곱과 오차분산의 합 으로 나눈 값 $\left\{(\Sigma \text { 요인적재량 })^{2} /\left[(\Sigma \text { 요인적재량 })^{2}+(\right.\right.$ 오차분산의 합)]\}이 곧 개념 신뢰도이다. 각 잠재요인별 측정항목의 내적 일 관성을 개념 신뢰도(construction reliability)를 통해 검증한다. 이러한 값을 Cronbach's $\alpha$ 로 나타내는데, 보통 0.7 이상이면 측 
Table 2. The items analyzed with average, standard deviation, skewness, kurtosis, correlation coefficient and variance inflation factor

\begin{tabular}{|c|c|c|c|c|c|c|c|}
\hline Scope & Item No. & Average & $\begin{array}{l}\text { Standard } \\
\text { deviation }\end{array}$ & Skewness & Kurtosis & $\begin{array}{c}\text { Correlation } \\
\text { coefficient }\end{array}$ & $\begin{array}{c}\text { Variance } \\
\text { inflation factor }\end{array}$ \\
\hline \multirow[t]{7}{*}{ Physical health } & $1-1$ & 3.54 & 1.305 & -0.325 & -1.223 & 0.550 & 2.904 \\
\hline & $1-2$ & 2.66 & 1.338 & 0.277 & -1.159 & 0.449 & 2.334 \\
\hline & $1-3$ & 3.02 & 1.172 & 0.119 & -0.967 & 0.522 & 2.675 \\
\hline & $1-4$ & 3.24 & 1.120 & -0.217 & -0.774 & 0.474 & 2.469 \\
\hline & $1-5$ & 4.01 & 0.971 & -0.846 & 0.142 & 0.541 & 2.898 \\
\hline & $1-6$ & 3.75 & 1.088 & -0.815 & 0.112 & 0.448 & 2.670 \\
\hline & $1-7$ & 3.52 & 1.268 & -0.435 & -0.921 & 0.371 & 1.980 \\
\hline \multirow[t]{10}{*}{ Emotional stability } & $1-8$ & 3.50 & 1.042 & -0.354 & -0.662 & 0.693 & 2.833 \\
\hline & $1-9$ & 3.43 & 1.089 & -0.379 & -0.628 & 0.750 & 3.591 \\
\hline & $1-10$ & 3.55 & 1.041 & -0.495 & -0.410 & 0.730 & 3.297 \\
\hline & $1-11$ & 3.52 & 1.131 & -0.386 & -0.697 & 0.723 & 4.084 \\
\hline & $1-12$ & 3.58 & 1.153 & -0.548 & -0.513 & 0.708 & 3.229 \\
\hline & $1-13$ & 3.66 & 1.079 & -0.633 & -0.234 & 0.705 & 3.871 \\
\hline & $1-14$ & 3.47 & 1.148 & -0.324 & -0.894 & 0.712 & 3.717 \\
\hline & $1-15$ & 3.48 & 1.131 & -0.528 & -0.468 & 0.691 & 3.186 \\
\hline & $1-16$ & 2.87 & 1.113 & 0.263 & -0.873 & 0.630 & 2.759 \\
\hline & $1-17$ & 3.18 & 1.062 & 0.000 & -0.572 & 0.740 & 3.468 \\
\hline \multirow[t]{13}{*}{ Dignity } & $2-1$ & 3.13 & 1.041 & 0.085 & -0.784 & 0.566 & 2.827 \\
\hline & $2-2$ & 3.63 & 0.991 & -0.547 & -0.082 & 0.571 & 2.587 \\
\hline & $2-3$ & 3.19 & 1.179 & -0.074 & -0.908 & 0.661 & 3.833 \\
\hline & $2-4$ & 3.22 & 1.129 & -0.096 & -0.818 & 0.602 & 3.882 \\
\hline & $2-5$ & 3.25 & 1.121 & -0.131 & -0.813 & 0.569 & 2.727 \\
\hline & $2-6$ & 3.20 & 1.198 & 0.012 & -1.135 & 0.643 & 2.866 \\
\hline & $2-7$ & 3.22 & 1.052 & -0.250 & -0.358 & 0.630 & 2.960 \\
\hline & $2-8$ & 3.23 & 1.031 & -0.167 & -0.697 & 0.668 & 3.231 \\
\hline & $2-9$ & 3.37 & 1.023 & -0.297 & -0.423 & 0.698 & 3.323 \\
\hline & $2-10$ & 3.55 & 1.094 & -0.580 & -0.369 & 0.705 & 3.277 \\
\hline & $2-11$ & 3.53 & 1.038 & -0.531 & -0.329 & 0.765 & 3.886 \\
\hline & $2-12$ & 3.29 & 1.122 & -0.252 & -0.829 & 0.625 & 3.270 \\
\hline & $2-13$ & 2.74 & 1.276 & 0.081 & -1.095 & 0.540 & 1.818 \\
\hline \multirow[t]{7}{*}{ Family relations } & $3-1$ & 3.72 & 1.034 & -0.712 & 0.159 & 0.583 & 2.608 \\
\hline & $3-2$ & 3.80 & 0.950 & -0.631 & -0.197 & 0.585 & 2.598 \\
\hline & $3-3$ & 4.06 & 0.809 & -0.622 & -0.032 & 0.322 & 2.056 \\
\hline & $3-4$ & 3.90 & 0.941 & -0.761 & 0.316 & 0.533 & 2.464 \\
\hline & $3-5$ & 3.49 & 1.031 & -0.322 & -0.536 & 0.668 & 3.059 \\
\hline & $3-6$ & 3.77 & 1.014 & -0.905 & 0.560 & 0.622 & 2.985 \\
\hline & $3-7$ & 3.59 & 1.124 & -0.453 & -0.696 & 0.665 & 3.234 \\
\hline \multirow{10}{*}{$\begin{array}{l}\text { Personal relations \& } \\
\text { communication }\end{array}$} & $4-1$ & 3.65 & 1.039 & -0.573 & -0.315 & 0.678 & 4.250 \\
\hline & $4-2$ & 3.44 & 1.122 & -0.286 & -0.824 & 0.667 & 4.232 \\
\hline & $4-3$ & 3.55 & 1.010 & -0.533 & -0.322 & 0.643 & 3.764 \\
\hline & $4-4$ & 3.98 & 0.933 & -0.856 & 0.405 & 0.50 & 3.389 \\
\hline & $4-5$ & 3.74 & 1.030 & -0.617 & -0.318 & 0.547 & 3.023 \\
\hline & 4-6 & 3.46 & 1.018 & -0.201 & -0.679 & 0.569 & 2.264 \\
\hline & $4-7$ & 3.56 & 0.931 & -0.644 & 0.095 & 0.504 & 2.366 \\
\hline & $4-8$ & 3.39 & 1.096 & -0.264 & -0.707 & 0.600 & 2.523 \\
\hline & $4-9$ & 3.85 & 0.888 & -0.773 & 0.524 & 0.537 & 2.645 \\
\hline & 4-10 & 3.55 & 1.097 & -0.492 & -0.610 & 0.631 & 3.570 \\
\hline
\end{tabular}


Table 2. The items analyzed with average, standard deviation, skewness, kurtosis, correlation coefficient and variance inflation factor (continued)

\begin{tabular}{cccccccc}
\hline Scope & Item No. & Average & $\begin{array}{c}\text { Standard } \\
\text { deviation }\end{array}$ & Skewness & Kurtosis & $\begin{array}{c}\text { Correlation } \\
\text { coefficient }\end{array}$ & $\begin{array}{c}\text { Variance } \\
\text { inflation factor }\end{array}$ \\
\hline $4-11$ & 3.28 & 1.173 & -0.418 & -0.795 & 0.534 & 2.320 \\
$4-12$ & 3.55 & 1.006 & -0.657 & 0.024 & 0.604 & 2.991 \\
$4-13$ & 3.88 & 0.872 & -0.710 & 0.541 & 0.573 & 3.046 \\
\\
$4-14$ & 3.64 & 0.982 & -0.629 & -0.076 & 0.586 & 2.637 \\
$4-15$ & 3.44 & 1.090 & -0.268 & -0.661 & 0.570 & 2.073 \\
\hline
\end{tabular}

정변수들의 내적일관성이 검증되어 집중타당도가 있다고 판단 되어 최종 선별된 문항들이 적절한 것으로 설명할 수 있다. 왜 냐하면 더 이상 문항들을 제거하지 않아도 내적 일관성이 구축 되었다고 생각되기 때문이다.

또한 판별 타당도 검증으로 평균분산추출(average variance extracted, AVE) 값을 사용한다. AVE 값이 요인 간 상관계수의 값보다 커야 판별 타당도가 있는 것으로 생각되는데, 왜냐하면 $\mathrm{AVE}$ 가 더 크면 요인 간 서로 상관이 없어 다른 영역을 평가하므 로 변별력이 향상된 척도로 생각할 수 있기 때문이다(Hong, 2000). 마지막으로 구조모형의 적합도를 평가하기 위해 표본 수 에 비교적 덜 민감하고 모형의 간명성을 고려하는 Turker-Lewis index (TLI), root mean error of approximation (RMSEA), 모형 의 오류를 측정하는 comparative fit index (CFI)도 함께 고려 하였다. TLI 및 CFI 지수는 0.9 이상일 때 적합한 구조모형으 로 평가할 수 있고(Bentler, 1990), RMSEA 지수는 0.05 이하 일 때 우수한 구조모형 적합도를 표시하지만 0.08 이하면 수용 가능한 적합도로 간주한다(Browne \& Cudeck, 1993).

\section{RESULTS}

\section{문항 분석}

52 개의 예비 문항의 평균, 표준편차, 왜도와 첨도, 상관계수, 분산팽창지수 값은 Table 2 와 같다. 본 연구에서 제시된 52개 문항을 각 문항별로 분석하였을 때 평균이 2.0 이하이거나 4.5 이상인 경우와 표준편차가 0.8 이하인 문항은 없었다. 또한 응 답의 편중도를 보여주는 왜도와 첨도의 경우, 왜도의 절대값은 $-0.856 \sim 0.277$ 이었고, 첨도의 절대값은 $-1.223 \sim 0.560$ 으로 그 변별력과 정규성에서 적절한 것으로 나타났다. 삶의 질 총점과 각 문항 응답 간의 상관계수를 산출하였는데, 그 결과, 상관계 수가 유의도 0.05 수준에서 0.42 0.79 사이의 값을 가지는 것으 로 나타나, 모든 문항이 유의미한 상관관계의 기준이 되는 0.3 이상의 상관계수를 가지고 있는 것을 확인할 수 있었다. 분산 팽창지수는 문항의 다중공선성을 확인하기 위한 지표인데, 이 값이 모두 5 미만으로 나타나, 다중공선성은 크게 문제가 되지 않는 것으로 나타났다.
Table 3. Extraction 10 factors through varimax rotation and the lastselected five factors through factor loading analysis (shaded factors)

\begin{tabular}{rrl}
\hline Factor & $\begin{array}{c}\text { Explanation } \\
\text { rate }(\%)\end{array}$ & \multicolumn{1}{c}{$\begin{array}{c}\text { Factor explanation question } \\
\text { (factor loading over 0.5) }\end{array}$} \\
\hline 1 & 11.252 & $2-1,2-3,2-4,2-5,2-7,2-9,2-11,2-12$ \\
2 & 10.922 & $3-7,4-1,4-2,4-3,4-4,4-5,4-9,4-10,4-13$ \\
3 & 8.104 & $1-1,1-2,1-3,1-4,1-5,1-6$ \\
4 & 6.237 & $1-11,1-12,1-13$ \\
5 & 5.929 & $4-6,4-7$ \\
6 & 5.565 & $3-1,3-2,3-3,3-4,3-6$ \\
7 & 5.490 & $4-11,4-14$ \\
8 & 3.109 & $1-7$ \\
9 & 1.723 & No question over explanation 0.5 \\
10 & 1.642 & No question over explanation 0.5 \\
\hline
\end{tabular}

\section{탐색적 요인분석}

본 52개 문항의 $\mathrm{KMO}$ 값은 0.930, Barlett의 구형성 검정 결 과는 카이제곱값이 8886.460( $p<0.001)$ 으로 해당 문항들이 요 인분석에 적합하면서 동시에 요인분석이 가능한 공통요인이 존재하는 것으로 나타났다.

요인구조의 회전방법으로 varimax 회전 10 번 반복을 통해, 고유 값이 1 이상인 요인이 10 개 추출되었고 10 개 요인에 의한 총 설명량은 $59.97 \%$ 였다(Table 3).

Table 4는 10 개 요인 간 상관계수를 분석한 결과이다. 직교 회전으로 요인이 추출되었기 때문에 요인 간의 상관계수는 매우 낮으며, 유의수준 0.05 에서 유의한 상관계수도 존재하지 않아 서 요인 간 상관은 없는 것으로 나타났다.

추출된 문항들의 신뢰도는 높으나, 지나치게 많은 요인이 추 출되는 것을 볼 때 문항 축소가 필요할 것으로 분석되었다. 따 라서 각 요인에 해당하는 문항과 문항 별 설명력을 나타내는 요 인부하량을 검증하여 이를 바탕으로 삶의 질을 구성하고 있는 요인들의 특성을 가장 잘 반영하는 문항을 선정하였다. 척도의 간명성을 높이기 위해 최대 요인부하량이 0.5 이상인 문항을 우선적으로 선별하고 이러한 문항이 3개 이상 속해 있는 요인만 을 최종 요인으로 선정하였다. 그 결과, 추출된 총 10 개의 요인 중 전체 변량의 $42.080 \%$ 를 설명하고 각 요인의 설명량이 전체 적으로 고르게 변화하여 의미 있는 다섯 개의 요인(factor 1,2 , 
Table 4. Correlation coefficient of the extracted 10 factors

\begin{tabular}{cccccccccc}
\hline Factor & 1 & 2 & 3 & 4 & 5 & 6 & 7 & 8 & 9 \\
\hline 1 & 1.000 & & & & & & & & \\
2 & 0.017 & 1.000 & & & & & & & \\
3 & 0.026 & 0.003 & 1.000 & & & & & \\
4 & 0.014 & 0.022 & 0.092 & 1.000 & & & & \\
5 & 0.041 & 0.017 & 0.020 & 0.049 & 1.000 & & & & \\
6 & 0.055 & 0.031 & 0.016 & 0.055 & 0.014 & 1.000 & & & \\
7 & 0.068 & 0.034 & -0.019 & 0.060 & 0.041 & 0.036 & 1.000 & & \\
8 & 0.030 & 0.036 & 0.051 & 0.049 & 0.009 & -0.022 & 0.017 & 1.000 & \\
9 & -0.023 & -0.014 & 0.020 & 0.010 & 0.041 & 0.005 & -0.003 & 0.038 & 1.000 \\
10 & 0.014 & -0.002 & -0.011 & -0.002 & 0.018 & -0.014 & 0.022 & -0.020 & -0.009 \\
\hline
\end{tabular}

$3,4,6$ )이 추출되었으며(Table 3), 문항의 개수는 총 31 개로 축 소되었다. 결과적으로 선정된 31개의 문항을 다섯 개의 요인별 로 정리하고 청각장애 장노년기의 삶의 질(Quality of Life in Adult and Elder with Hearing Loss, QOL-AEHL)을 최종적 으로 제작하였다(Appendix 2). 해당 문항들이 내적 일관성을 가지고 있는지 Cronbach's $\alpha$ 로 신뢰도를 측정한 결과, 제 1 요인 은 0.886 , 제 2 요인은 0.910 , 제 3 요인은 0.839 , 제 4 요인은 0.838 , 제 5 요인은 0.788 로 전체적으로 0.8 에 준하는 높은 신뢰도를 확 보하였으며, 전체 31 문항에 대한 신뢰도 또한 0.941 로 매우 높 게 나타났다. 다섯 개의 요인은 구성문항들의 특성을 중심으로 제 1 요인은 '자존감', 제2요인은 '대인관계와 의사소통', 제 3 요인 은 '신체적 건강', 제 4 요인은 '정서적 안정', 제 5 요인은 '가족관계' 로 명명하였다. 총 8 개의 문항으로 구성된 제 1 요인인 '자존감'은 전체 변량의 $11.25 \%$ 를 설명하고, 자기 자신의 능력에 대한 심리 적인 불안감과 상실감에 관한 문항으로 구성되어 있다. 제 2 요인 인 '대인관계와 의사소통'은, 전체 변량의 $10.92 \%$ 를 설명하고 대 인 관계에서 겪는 어려움에 관한 9 개의 문항들로 구성되어 있 다. 제 3 요인인 '신체적 건강'은 전체 변량의 $8.10 \%$ 를 설명하고 자 신이 체감하는 신체적인 한계와 피로도에 대한 6 개의 문항으로 구성되어 있다. 제4요인인 '정서적 안정'은 전체 변량의 $6.25 \%$ 를 설명하고, 자신이 정신적 상태에 대한 3 개의 문항으로 구성되어 있다. 마지막으로 제5요인인 '가족관계'는 전체 변량의 $5.58 \%$ 를 설명하고 가족들과의 관계에 대한 5 개 문항으로 구성되어 있 다. 다섯 개의 모든 요인이 전체 변량의 최소 $5 \%$ 이상의 설명도 를 나타내서 청각장애 장노년기의 삶의 질에 대한 설명력을 고 르게 가지고 있는 것으로 나타났다.

\section{확인적 요인분석}

\section{신뢰도 및 집중타당도 검증}

탐색적 요인분석에서 추출된 다섯 개 요인에 대한 확인적 요 인분석은 최대우도법을 사용하였다. 구조모형의 적합도 평가에
앞서, 요인별 측정항목의 내적 일관성을 검증하기 위하여 신뢰 도를 Cronbach's $\alpha$ 로 분석한 결과 모든 잠재요인에 대한 신뢰 성 계수는 0.7 이상으로 나타났다. 따라서 최종 선정된 문항은 0.6 이상의 권장 수준을 만족하여 높은 내적 일관성을 가진 척 도임을 확인할 수 있었고, 또한 모든 문항들 중, 제거되었을 때 에 각 요인의 신뢰도가 상승하는 문항이 없으므로, 더 이상 제 거할 문항을 찾을 수 없었고 본 구조 모형은 높은 일관성을 보 이는 문항들로 선별되었음을 검증하였다. 한편 다섯 개 요인 구 조모형의 문항들이 척도의 구성개념을 일관되게 잘 측정하고 있는지를 판단하기 위하여 집중타당도를 평가한 결과, 모든 문 항의 표준화요인부하량이 평가 기준치(0.5 이상)를 충족시켰으 며 임계비가 1.96 이상으로 통계적 유의성을 나타냈다 $(p<0.05)$. 개념 신뢰도는 모든 요인이 기준치인 0.6 이상을 상회하여 본 구 조모형의 집중타당도가 검증되었다. 아래 Table 5 는 각 요인별 신뢰도와 집중타당도에 관련된 수치를 보여준다.

\section{판별타당도 검증}

판별타당도는 각 요인들이 서로 얼마나 변별력을 가지고 있 는가를 의미한다. 판별타당도를 확인하기 위해서는 각 요인의 표준분산추출이 두 요인 간 상관관계의 제곱보다 큰지 살펴보 았다. Table 6에서 볼 수 있듯이 모든 요인 간의 상관관계 제곱 값이 각 AVE보다 0.1 이상 작아 각 요인별 변별이 있는 것을 확인할 수 있었으나 요인 1인 '자존감과 요인 4인 '정서적 안정' 간의 상관관계는 0.458 로 해당 $\mathrm{AVE}$ 보다는 작았지만, 크게 변 별이 있지는 않았다. 따라서 본 측정모형은 전반적으로 요인 간 상관성이 낮은 독립적인 요인들로 구성되어 있음이 확인되었다.

\section{구조모형의 적합도 평가}

최종 선정된 31개 문항의 적합도 지수는 TLI가 0.862, CFI가 0.874, RMSEA가 0.063이었다. 따라서 TLI 및 CFI 지수는 기 준에 다소 미치지 못하지만 RMSEA 지수는 기준을 충족시키 는 것으로 나타났다. 따라서 본 구조모형의 적합도는 비교적 요 
인에 따른 구성개념을 평가하는 데 적합하다고 해석될 수 있다. 할 수 있는 도구를 개발하기 위하여 삶의 질 개념 기틀을 선정

\section{DISCUSSIONS}

본 연구는 청각장애를 가진 장노년기 성인의 삶의 질을 측정 $\mathrm{AEHL}$ ) 척도를 개발하였다.
하고 그 틀에 맞는 예비 문항 52개를 선정한 뒤 500명의 청각장 애 장노년기를 대상으로 문항분석 및 탐색적 요인 분석을 통한 최종문항 31개를 선정하여 청각장애 장노년기 삶의 질(QOL-

Table 5. Construction reliability and concentrate validity for each factors

\begin{tabular}{|c|c|c|c|c|c|c|}
\hline Scope & Item No. & C.R. & $p$ & $\begin{array}{c}\text { Standardized factor } \\
\text { loading value }\end{array}$ & CR & Cronbach's $\alpha$ \\
\hline \multirow[t]{8}{*}{ Dignity } & $2-1$ & 7.517 & 0.000 & 0.502 & 0.841 & 0.871 \\
\hline & $2-3$ & 10.382 & 0.000 & 0.69 & & \\
\hline & $2-4$ & 8.838 & 0.000 & 0.589 & & \\
\hline & $2-5$ & 9.197 & 0.000 & 0.612 & & \\
\hline & $2-7$ & 9.045 & 0.000 & 0.602 & & \\
\hline & $2-9$ & 8.735 & 0.000 & 0.582 & & \\
\hline & $2-11$ & 10.96 & 0.000 & 0.728 & & \\
\hline & $2-12$ & \multicolumn{2}{|c|}{ Fixed regression weight } & 0.729 & & \\
\hline \multirow[t]{9}{*}{ Personal relations \& communication } & $3-7$ & 8.477 & 0.000 & 0.736 & 0.886 & 0.906 \\
\hline & $4-1$ & 8.491 & 0.000 & 0.738 & & \\
\hline & $4-2$ & 8.279 & 0.000 & 0.707 & & \\
\hline & $4-3$ & 7.467 & 0.000 & 0.601 & & \\
\hline & $4-4$ & 7.487 & 0.000 & 0.604 & & \\
\hline & $4-5$ & 8.028 & 0.000 & 0.672 & & \\
\hline & $4-9$ & 8.198 & 0.000 & 0.695 & & \\
\hline & $4-10$ & 8.917 & 0.000 & 0.806 & & \\
\hline & $4-13$ & \multicolumn{2}{|c|}{ Fixed regression weight } & 0.553 & & \\
\hline \multirow[t]{6}{*}{ Physical health } & $1-1$ & 8.77 & 0.000 & 0.722 & 0.82 & 0.830 \\
\hline & $1-2$ & 7.558 & 0.000 & 0.589 & & \\
\hline & $1-3$ & 8.611 & 0.000 & 0.702 & & \\
\hline & $1-4$ & 7.835 & 0.000 & 0.617 & & \\
\hline & $1-5$ & 8.45 & 0.000 & 0.684 & & \\
\hline & $1-6$ & \multicolumn{2}{|c|}{ Fixed regression weight } & 0.62 & & \\
\hline \multirow[t]{3}{*}{ Emotional stability } & $1-11$ & 9.31 & 0.000 & 0.656 & 0.719 & 0.799 \\
\hline & $1-12$ & 9.53 & 0.000 & 0.672 & & \\
\hline & $1-13$ & \multicolumn{2}{|c|}{ Fixed regression weight } & 0.706 & & \\
\hline \multirow[t]{5}{*}{ Family relations } & $3-1$ & 9.805 & 0.000 & 0.677 & 0.83 & 0.814 \\
\hline & $3-2$ & 9.182 & 0.000 & 0.743 & & \\
\hline & $3-3$ & 9.78 & 0.000 & 0.686 & & \\
\hline & $3-4$ & 9.083 & 0.000 & 0.745 & & \\
\hline & $3-6$ & \multicolumn{2}{|c|}{ Fixed regression weight } & 0.66 & & \\
\hline
\end{tabular}

C.R.: critocal ratio, CR: construction reliability

Table 6. Interval latent factor discriminant validity

\begin{tabular}{|c|c|c|c|c|c|c|}
\hline & AVE value & $\begin{array}{l}\text { Factor } 1 \\
\text { (dignity) }\end{array}$ & $\begin{array}{c}\text { Factor } 2 \\
\text { (personal relations \& } \\
\text { communication) }\end{array}$ & $\begin{array}{c}\text { Factor } 3 \\
\text { (pysical health) }\end{array}$ & $\begin{array}{c}\text { Factor } 4 \\
\text { (emotional stability) }\end{array}$ & $\begin{array}{c}\text { Factor } 5 \\
\text { (family relations) }\end{array}$ \\
\hline Factor 1 (dignity) & 0.402 & 1.000 & & & & \\
\hline $\begin{array}{l}\text { Factor } 2 \text { (personal relations \& } \\
\text { communication) }\end{array}$ & 0.467 & 0.376 & 1.000 & & & \\
\hline Factor 3 (pysical health) & 0.432 & 0.230 & 0.060 & 1.000 & & \\
\hline Factor 4 (emotional stability) & 0.460 & 0.458 & 0.403 & 0.157 & 1.000 & \\
\hline Factor 5 (family relations) & 0.494 & 0.316 & 0.408 & 0.066 & 0.248 & 1.000 \\
\hline
\end{tabular}


일반적으로 삶의 질 척도 개발 연구의 내적 일관도는 0.6 0.9 정도로 본 연구와 유사한 결과를 보였다. 예를 들면 Umansky et al.(2011)는 HEAR-QL로 7 12세 아동을 대상으로 삶의 질 을 측정하는 연구에서 Cronbach's $\alpha$ 값이 0.97로 매우 높게 나타 났다. 대상이 청각장애 청소년인 Patrick et al.(2011)도 YQOL$\mathrm{DHH}$ 연구에서도 Cronbach's $\alpha$ 값이 0.84로 나타났다. 또한 일반 적인 삶의 질 척도인 한국판 WHOLQOL-BREF로 일반 성인 을 대상으로 연구한 Min et al.(2000)의 연구에서 Cronbach's $\alpha$ 값은 0.898 이었다. 그 외 척도 개발에 관한 연구인 Cho(2003) 의 청소년 자원봉사 만족도 척도개발의 연구에서는 Cronbach' $\mathrm{s} \alpha$ 값이 0.862 이고 각 요인별로는 1 요인인 청소년 지원은 0.738 , 2요인인 집단활동은 $0.684,3$ 요인인 봉사성과는 0.702 , 4요인인 학습성장은 0.676 등 모두 양호하게 나타났지만, 모두 0.8 이하 였다. 본 연구에서 개발한 QOL-AEHL의 Cronbach's $\alpha$ 값은 0.941 로 나타나 성인 대상으로 한 척도 중 Min et al.(2000)에 의해 개 발된 한국판 WHOQOL-BREF의 Cronbach's $\alpha$ 값 0.898보다 높게 나타났다. 세부 요인별로 분석한 신뢰도는 제1요인인 '자 존감'은 0.886 , 제2요인인 '대인관계와 의사소통'은 0.910 , 제 3 요 인인 '신체적 건강'은 0.839 , 제 4 요인인 '정신적 안정'은 0.838 , 제 5 요인인 가족관계는 0.788 로 대체적으로 높게 나타나 QOL-AE$\mathrm{HL}$ 은 청각장애 장노년기의 삶의 질을 전반적으로 검사하기에 적절할 뿐 아니라 각 요인별 검사항목도 각 요인에 적절한 검사 항목으로 구성되어 있는 것을 확인할 수 있었다.

평가도구의 요인은 측정하고자 하는 목적을 적절히 적용할 수 있는지 확인하기 위해 중요하다. 삶의 질을 측정하는 여러 다른 척도 중 보편적으로 많이 활용되고 있는 $\mathrm{WHO}-\mathrm{QOL}$ 은 일반적인 건강상의 요인들을 통해 삶의 질을 측정한다. 하지만, 이번에 개발된 QOL-AEHL은 장노년기 중 청각장애를 가지고 있는 대상으로 하기 때문에 그 대상에 맞는 요인인 대인관계 등 의 요인들이 포함되면서 변별력을 가지게 되었고, 또한 일반적인 건강 요인도 포함시켜 편중적인 요인들로 구성되지 않도록 조절하 였다. 예를 들어 HEAR-QL (Umansky et al., 2011)이나 KINDL (Ravens-Sieberer \& Bullinger, 1998) 등의 문항은 대인관계에 대한 부분을 요인으로 선정하여 가족이나 아동의 교우관계에 관한 부분을 질문하는 문항이 비교적 많았다. 그러나 장노년기 를 대상으로 분석한 QOL-AEHL은 예비문항 중 가족관계와 관련된 문항이 일관되지 않은 요인분석 결과로 나타나 전체 문 항의 신뢰도를 저하시켰다. 따라서 그러한 문항들이 제거되는 현상이 나타났다. 아마도 장노년기의 대인관계는 가족이나 교 우관계가 중요한 아동이나 청소년기보다 덜 중요한 요인이기 때 문인 것으로 생각된다.

본 연구는 장노년기의 삶의 질 척도를 개발하기 위해 요인분 석을 통해 각 요인별 문항을 신뢰도와 타당도를 분석하였다. 이
는 설문의 내용들이 연구하고자 하는 대상을 얼마나 잘 대변 하는가에 있어 매우 중요하다. 만약 이러한 부분을 잘 인지하 지 못한다면 수천 명이나 수만 명을 대상으로 연구하여도 잘못 된 결론을 도출할 것이다. 이미 많은 연구에서 요인분석을 통해 척도를 개발한 사례가 있는데, Choi \& Park(2015)은 미국의 디 지털 시민성 척도 개발 후속 연구로, 한국의 정치·사회·문화적 상황에 맞는 디지털 시민성 척도를 탐색적, 확인적 요인을 통해 신뢰도와 타당도를 연구하였고, Park(2008)은 탐색적 요인분 석을 통해 심리학적 측면에 따른 무용정서는 무용성격 및 무 용동기, 인간의 사상, 생각, 경험이 있다고 밝힌 적이 있다. 이들 연구도 본 연구와 같이 문항분석, 신뢰도 분석, 탐색적 요인분 석, 확인적 요인분석을 통해 검증을 하였는데, 먼저 무용정서 연구에서는 주성분분석을 통해 회전을 시킨 결과 총 222 개 문 항 중 48 개 문항이 추출되어 전체 분산의 $79.658 \%$ 를 설명하였 고, Cronbach's $\alpha$ 값은 0.936 이상으로 나타났다. 디지털 시민성 척도에서는 $\mathrm{KMO}$ 측도값은 0.84 , Bartlett의 구형성 검정 값은 6380.04 유의수준은 0.000 으로 나타나 요인분석이 가능한 공 통요인이 존재하는 것으로 확인하였고, 상관행렬표 분석 결과 문항 간 상관관계가 0.8 로 나타나 다중공선성에도 문제가 없었 다. 요인분석 방법은 직교회전 방법을 사용하였고 그 결과 36 개 문항 중 23개 문항이 추출되었고 전체 설명량이 $38 \%$ 이상 나타났다. Cronbach's $\alpha$ 값은 0.81로 나타났고, 확인적 요인분석 결과 $\mathrm{GFI}$ 값은 $0.871, \mathrm{CFI}$ 값은 $0.874, \mathrm{RMSEA}$ 값은 0.076으 로 나타나 모형 적합도가 적당하여 각 연구에서 검증하고자 하 는 부분들의 신뢰도와 타당도가 모두 검증이 되었다. 따라서 본 연구도 상기 연구들과 같이 그러한 과정을 진행하였기에 장 노년기 삶의 질 측정 도구로 적절할 수 있다고 볼 수 있었다.

QOL-AEHL은 청력정도에 따른 보청기 사용으로 나타나는 삶의 질에 대한 변화를 평가하는 유용한 도구가 될 수도 있을 것으로 생각된다. 예를 들어, Kuo(2010)가 개발한 Korean evaluation Scale for hearing handicap이나 Cox \& Alexander(1995) 가 개발한 도구를 해석한 보청기 만족도 척도인 Abbreviated Profile of Hearing Aid Benefit 등과 병행하여 연구한다면, 보 청기 만족도, 청각장애 지수, 삶의 질 평가를 체계적으로 분석 할 수 있어 어느 요인이 장노년기의 삶의 질에 어떠한 영향을 미 치는지에 대해 연계하여 구체적이고 체계적인 분석이 가능할 것이다. 이러한 자료는 실질적으로 청각장애 장노년기의 삶의 질을 높일 수 있는 기반이 되어 청각장애 장노년기의 삶의 질의 부족한 부분을 적절히 평가하여 해결할 수 있는 실마리를 제 공함으로 실질적인 복지구현에 이바지할 수 있을 것이다.

향후 개발된 척도를 표준화하는 작업이 필요한데, 정상 청력 을 가지고 있는 장노년기를 대상으로도 검사를 하여 표준화된 설문 문항을 확보할 필요가 있으며, 표준화 작업을 통해 장노년 
기 청각장애인이 삶의 질이 어느 정도인지를 객관적인 지표로

서 활용할 수 있다.

표준화하는 과정에서 타당도와 신뢰도를 정확히 분석하는 작업 등이 있어야 되는데 청각장애인의 삶의 질 평가 척도와 유사한 척도를 분석하여 상관관계가 높을수록 개발된 척도의 타당도가 더 있는 것으로 분석하는 수렴 타당도와 반대로 상 관이 없는 척도를 함께 분석해 상관관계가 없을수록 개발되어 진 척도의 타당도가 높은 것으로 보는 변별타당도를 추가적으 로 분석할 필요가 있다. 이러한 표준화 작업으로 QOL-AEHL 은 장노년기의 청각장애인의 삶의 질을 평가하는 데 간편하고 유용하게 사용될 수 있을 것이며 이러한 도구의 개발과 사용 은 청각장애로 인한 삶의 질에 대한 평가로 청각장애 장노년기 인구가 받는 사회적 능력의 저하를 최소화할 수 있어 실질적으 로 장노년기 청각장애인의 복지를 구현하는 데 이바지할 수 있 을 것이다.

중심 단어 : 삶의 질·청각장애 장노년기의 삶의 질·요인분석· 청력손실·장노년기.

\section{REFERENCES}

Aaronson, N. K., Ahmedzai, S., Bergman, B., Bullinger, M., Cull, A., Duez, N. J., et al. (1993). The European organization for research and treatment of cancer QLQ-C30: A quality-of-life instrument for use in international clinical trials in oncology. Journal of the National Cancer Institute, 85(5), 365-376.

Bentler, P. M. (1990). Comparative fit indexes in structural models. Psychological Bulletin, 107(2), 238.

Boyer, J. G. \& Earp, J. A. L. (1997). The development of an instrument for assessing the quality of life of people with diabetes: Diabetes-39. Medical Care, 35(5), 440-453.

Browne, M. W. \& Cudeck, R. (1993). Alternative ways of assessing model fit. Sage Focus Editions, 154, 136-136.

Cella, D. F. (1997). Manual of the Functional Assessment of Chronic Illness Therapy (FACIT) measurement system (version 4). Center on Outcomes, Research and Education (CORE). Evanston, IL: Evanston Northwestern Healthcare and Northwestern University.

Cho, S. W. (2003). Developing volunteer satisfaction scale for Korean adolescent (unpublished master's thesis). Sungkyunkwan University, Seoul.

Choi, I. J. (2007). Development and validation study of the Korean version of parent-child relationship instrument. The Korea Journal of Youth Counseling, 15(2), 45-56.

Choi, M. S. \& Park, H. J. (2015). A validation study on the Korean digital citizenship scale through exploratory and confirmatory factor analysis. Theory and Research in Citizenship Education, 47(4), 273-297.

Cox, R. M. \& Alexander, G. C. (1995). The abbreviated profile of hearing aid benefit. Ear and Hearing, 16(2), 176-186.

Harper, A. (1998). Development of the World Health Organisation WHOQOL-BREF quality of life assessment. Psychological Medicine, 28(3), 551-558.

Hong, S. H. (2000). The criteria for selecting appropriate fit indices in structural equation modeling and their rationales. Korean Journal of Psychology, 19(1), 161-177

Juniper, E. F., Rohrbaugh, T., \& Meltzer, E. O. (2003). A questionnaire to measure quality of life in adults with nocturnal allergic rhinoconjunctivitis. Journal of Allergy and Clinical Immunology, 111(3), 484-490.

Karnofsky, D. A. \& Burchenal, J. H. (1949). The Clinical Evaluation of Chemotherapeutic Agents in Cancer. New York, NY: Columbia University Press.

Ku, H. L. \& Kim, J. S. (2010). The development of the Korean Evaluation Scale for Hearing Handicap (KESHH) for the geriatric hearing loss. Journal of the Korea Gerontological Society, 30(3), 973-992.

Lee, E. H. (2007). [Development and psychometric evaluation of a quality of life scale for Korean patients with cancer (C-QOL)]. Taehan Kanho Hakhoe Chi, 37(3), 324-333.

Lee, H. S. \& Park, E. (2015). Development and evaluation of Allergic Rhinitis Disease-Specific Quality of Life (AR-QOL) scale for adult in Korea. INC 2015 10th International Nursing Conference. p.429.

Min, S. K., Lee, C. I., Kim, K. I., Suh, S. Y., \& Kim, D. K. (2000). Development of Korean version of WHO quality of life scale abbreviated version (WHOQOL-BREF). Journal of Korean Neuropsychiatric Association, 39(3), 571-579.

Padilla, G. V., Presant, C., Grant, M. M., Metter, G., Lipsett, J., \& Heide, F. (1983). Quality of life index for patients with cancer. Research in Nursing and Health, 6(3), 117-126.

Park, S. H. (2008). An exploration into the psychological factors of dancer emotion (unpublished doctor's thesis). Kookmin University, Seoul.

Patrick, D. L., Edwards, T. C., Skalicky, A. M., Schick, B., Topolski, T. D., Kushalnagar, P., et al. (2011). Validation of a quality-of-life measure for deaf or hard of hearing youth. Otolaryngology and Head and Neck Surgery, 145(1), 137-145.

Ravens-Sieberer, U. \& Bullinger, M. (1998). Assessing health-related quality of life in chronically ill children with the German KINDL: First psychometric and content analytical results. Quality of Life Research, 7(5), 399-407.

Umansky, A. M., Jeffe, D. B., \& Lieu, J. E. (2011). The HEAR-QL: Quality of life questionnaire for children with hearing loss. Journal of the American Academy of Audiology, 22(10), 644-653. 


\section{APPENDIX}

Appendix 1. 52 Finally Selected Preliminary List with Five Factors of Physical Health, Mental Health, Self-Esteem, Personal Relation, and Family Relation

\section{1. 건강영역(신체적)}

1-1. 나는 걷는 데 지장이 있다.

1-2. 나는 격렬한 운동(달리기, 자전거 등)을 하는 것이 힘들다.

1-3. 나는 아프다고 느낀다.

1-4. 나는 피곤하고 매우 지쳐 있다.

1-5. 나는 스스로 옷을 입거나 씻을 때 불편함을 느낀다.

1-6. 나는 가사일을 하기가 어렵다.

1-7. 나는 잠을 잘 못 잔다.

\section{1. 건강영역(정신적)}

1-8. 나는 초조하고 긴장된다.

1-9. 나는 인생을 즐기지 못 한다.

1-10. 나의 삶은 매우 의미가 없다.

1-11. 나는 우울감 같은 부정적인 감정을 자주 느낀다.

1-12. 나는 즐겁게 많이 웃지 못한다.

1-13. 나는 지루하다.

1-14. 나는 외롭다.

1-15. 나는 무섭고 나 자신에 대해 확신이 없다.

1-16. 나는 기억력이 좋지 않다.

1-17. 나는 집중을 잘 못한다.

\section{2. 자존감(경제적)}

2-1. 나는 필요한 만큼의 충분한 돈을 가지고 있지 않다.

2-2. 나는 내가 살고 있는 장소에 대해 만족하지 못한다.

2-3. 나는 내 노후생활이 걱정된다.

2-4. 나의 현재 재정 상태는 안정적이지 못하다.

\section{2. 자존감(여가)}

2-5. 나는 레저(여가) 활동을 위한 충분한 기회를 가지지 못한다.

2-6. 나는 텔레비전, 라디오 등을 시청하거나 청취하는 데 문제 가 있다.

\section{2. 자존감(일 또는 직업)}

2-7. 나는 내가 필요로 하는 정보를 쉽게 구할 수 없다.

2-8. 나는 나의 능력에 자신이 없다.
2-10 나는 안 좋은 생각들을 많이 한다.

2-11. 나는 인생을 즐기지 못하며 의욕적인 생활을 하지 못한다.

2-12. 나는 내가 하고 싶은 일을 못하고 산다.

2-13. 나는 나의 성생활에 만족하지 못한다.

\section{3. 가족관계}

3-1. 나는 나의 가족들(부모님, 자녀, 배우자)과 잘 지내지 못한다.

3-2. 나는 집에서 평안함을 못 느낀다.

3-3. 나는 집에서 가족들과 싸운다.

3-4. 나의 가족들은 내가 하려고 하는 일을 하지 못하게 한다.

3-5. 나는 나의 감정을 가족들에게 잘 애기 하지 못한다.

3-6. 나는 가족에 대해 만족하지 못한다.

3-7. 나는 가족들과 의사소통하는 데 문제가 있다.

4. 대인관계(만남 및 모임)

4-1. 나는 다른 사람들과 잘 어울리지 못한다.

4-2. 나는 모임에 자발적으로 참여하지 못한다.

4-3. 나는 낮선 사람들과 만나면 불편하다.

4-4. 나는 사람들과 만나는 것이 짜증난다.

4-5. 나는 사람들과 만나면 신경이 예민해진다.

\section{4. 대인관계(주변의 지지)}

4-6. 나는 다른 사람에게 도움이 필요할 때도 요청하지 못한다/ 않는다.

4-7. 나는 잘못을 지적 받아도 고치지 못한다.

4-8. 나는 다른 사람을 도와주지 못한다.

4-9. 나는 다른 사람들과 함께 일하는 것을 좋아하지 않는다. 4-10. 나는 다른 사람들과 의사소통 하는데 문제가 있다.

\section{4. 대인관계(심리적)}

4-11. 나는 나와 친한 사람들을 잃을까 걱정된다.

4-12. 나는 사람들이 나를 이해하지 못할까봐 걱정된다.

4-13. 나는 사람들이 나를 안 좋아한다고 느낀다.

4-14. 나는 다른 사람들과는 다르다고 느낀다.

4-15. 나는 혼자 있고 싶을 때가 있다.

\section{2. 자존감(심리적)}

2-9. 나는 자신에 대해 자랑스럽지 못하다. 
Appendix 2. Quality of Life in Adult and Elder with Hearing Loss

\begin{tabular}{|c|c|c|c|c|c|c|c|}
\hline 요인 & 문항 & 내 & $\begin{array}{c}\text { (1) } \\
\text { 매우 } \\
\text { 그렇다 } \\
\end{array}$ & \begin{tabular}{|c|} 
(2) \\
조금 \\
그렇다 \\
\end{tabular} & $\begin{array}{c}\text { (3) } \\
\text { 그저 } \\
\text { 그렇다 }\end{array}$ & $\begin{array}{c}\text { (4) } \\
\text { 그렇지 } \\
\text { 않다 } \\
\end{array}$ & $\begin{array}{c}\text { (5) } \\
\text { 전혀 } \\
\text { 그렇지않다 }\end{array}$ \\
\hline \multirow{8}{*}{$\begin{array}{c}\text { 1요인 } \\
\text { (자존감) }\end{array}$} & $1-1$ & 나는 필요한 만큼의 충분한 돈을 가지고 있지 않다. & & & & & \\
\hline & $1-2$ & 나는 내 노후생활이 걱정된다. & & & & & \\
\hline & $1-3$ & 나는 현재의 재정상태가 안정적이지 못하다. & & & & & \\
\hline & $1-4$ & 나는 레저(여가) 활동을 위한 충분한 기회를 가지지 못한다. & & & & & \\
\hline & $1-5$ & 나는 내가 필요로 하는 정보를 쉽게 구할 수 없다. & & & & & \\
\hline & $1-6$ & 나는 자신에 대해 자랑스럽지 못하다. & & & & & \\
\hline & $1-7$ & 나는 인생을 즐기지 못하며, 의욕적인 생활을 하지 못한다. & & & & & \\
\hline & $1-8$ & 나는 내가 하고 싶은 일을 못하고 산다. & & & & & \\
\hline \multirow{9}{*}{$\begin{array}{c}\text { 2요인 } \\
\text { (대인 관계와 } \\
\text { 의사 소통) }\end{array}$} & $2-1$ & 나는 가족들과 의사소통하는 데 문제가 있다. & & & & & \\
\hline & $2-2$ & 나는 다른 사람들과 잘 어울리지 못한다. & & & & & \\
\hline & $2-3$ & 나는 모임에 자발적으로 참여하지 못한다. & & & & & \\
\hline & $2-4$ & 나는 낯선 사람들과 만나면 불편하다. & & & & & \\
\hline & $2-5$ & 나는 사람들과 만나는 것이 짜증난다. & & & & & \\
\hline & $2-6$ & 나는 사람들과 만나면 신경이 예민해진다. & & & & & \\
\hline & $2-7$ & 나는 다른 사람들과 함께 일하는 것을 좋아하지 않는다. & & & & & \\
\hline & $2-8$ & 나는 다른 사람들과 의사소통하는 데 문제가 있다. & & & & & \\
\hline & $2-9$ & 나는 사람들이 나를 안 좋아한다고 느낀다. & & & & & \\
\hline \multirow{6}{*}{$\begin{array}{c}\text { 3요인 } \\
\text { (신체적 건강) }\end{array}$} & $3-1$ & 나는 걷는 데 지장이 있다. & & & & & \\
\hline & $3-2$ & 나는 격렬한 운동(달리기, 자전거 등)을 하는 것이 힘들다. & & & & & \\
\hline & $3-3$ & 나는 아프다고 느낀다. & & & & & \\
\hline & $3-4$ & 나는 피곤하고 매우 지쳐 있다. & & & & & \\
\hline & $3-5$ & 나는 스스로 옷을 입거나 씻을 때 불편함을 느낀다. & & & & & \\
\hline & $3-6$ & 나는 가사일을 하기가 어렵다. & & & & & \\
\hline \multirow{3}{*}{$\begin{array}{c}\text { 4요인 } \\
\text { (정서적 안정) }\end{array}$} & $4-1$ & 나는 우울감 같은 부정적인 감정을 자주 느낀다. & & & & & \\
\hline & $4-2$ & 나는 즐겁게 많이 웃지 못한다. & & & & & \\
\hline & $4-3$ & 나는 지루하다. & & & & & \\
\hline \multirow{5}{*}{$\begin{array}{c}\text { 5요인 } \\
\text { (가족 관계) }\end{array}$} & $5-1$ & 나는 나의 가족들(부모님, 자녀, 배우자)과 잘 지내지 못한다. & & & & & \\
\hline & $5-2$ & 나는 집에서 평안함을 못 느낀다. & & & & & \\
\hline & $5-3$ & 나는 집에서 가족들과 싸운다. & & & & & \\
\hline & $5-4$ & 나는 가족들이 내가 하려고 하는 일을 하지 못하게 한다. & & & & & \\
\hline & $5-5$ & 나는 가족에 대해 만족하지 못한다. & & & & & \\
\hline
\end{tabular}

